\title{
Bone Metastases, Skeletal-Related Events, and Survival in Patients With Metastatic Non-Small Cell Lung Cancer Treated With Immune Checkpoint Inhibitors
}

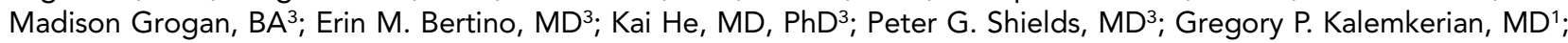

Shirish M. Gadgeel, MBBS ${ }^{1,5}$; Nithya Ramnath, MBBS ${ }^{1}$; Bryan J. Schneider, MD¹; Khaled A. Hassan, MD, MS1,6;

Nicholas Szerlip, MD; Zoey Chopra, BA ${ }^{8}$; Sara Journey, BS ${ }^{8}$; Jessica Waninger, BA, BS ; Daniel Spakowicz, PhD²,3;

David P. Carbone, MD, $\mathrm{PhD}^{3}$; Carolyn J. Presley, MD, MHS ${ }^{3}$; Gregory A. Otterson, MD³.

Michael D. Green, MD, PhD; ; and Dwight H. Owen, MD, $\mathrm{MSc}^{3}$

\begin{abstract}
Background: Bone metastases and skeletal-related events (SREs) are a frequent cause of morbidity in patients with metastatic non-small cell lung cancer (mNSCLC). Data are limited on bone metastases and SREs in patients with $\mathrm{mNSCLC}$ treated using immune checkpoint inhibitors (ICls), and on the efficacy of bone-modifying agents (BMAs) in this setting. Here we report the incidence, impact on survival, risk factors for bone metastases and SREs, and impact of BMAs in patients with $\mathrm{mNSCLC}$ treated with ICls in a multi-institutional cohort. Patients and Methods: We conducted a retrospective study of patients with $\mathrm{mNSCLC}$ treated with ICls at 2 tertiary care centers from 2014 through 2017. Overall survival (OS) was compared between patients with and without baseline bone metastases using a log-rank test. A Cox regression model was used to evaluate the association between $\mathrm{OS}$ and the presence of bone metastases at $\mathrm{ICl}$ initiation, controlling for other confounding factors. Results: We identified a cohort of 330 patients who had received ICls for metastatic disease. Median patient age was 63 years, most patients were treated in the second line or beyond $(n=259 ; 78 \%)$, and nivolumab was the most common $\mathrm{ICl}(\mathrm{n}=211 ; 64 \%)$. Median OS was 10 months $(95 \% \mathrm{Cl}$, 8.4-12.0). In our cohort, 124 patients (38\%) had baseline bone metastases, and 43 (13\%) developed SREs during or after ICl treatment. Patients with bone metastases had a higher hazard of death after controlling for performance status, histology, line of therapy, and disease burden (hazard ratio, 1.57; $95 \% \mathrm{Cl}, 1.19-2.08 ; P=.001$ ). Use of BMAs was not associated with OS or a decreased risk of SREs. Conclusions: Presence of bone metastases at baseline was associated with a worse prognosis for patients with $\mathrm{mNSCLC}$ treated with $\mathrm{ICl}$ after controlling for multiple clinical characteristics. Use of BMAs was not associated with reduced SREs or a difference in survival.
\end{abstract}

J Natl Compr Canc Netw 2021;19(8):915-921 doi: $10.6004 /$ jnccn.2020.7668

${ }^{1}$ Division of Hematology and Oncology, University of Michigan, Ann Arbor,

Michigan; ${ }^{2}$ Center for Biostatistics, ${ }^{3}$ Division of Medical Oncology, and ${ }^{4}$ Department of Internal Medicine, The Ohio State University, Columbus, Ohio; ${ }^{5}$ Division of Hematology and Oncology, Henry Ford Cancer Center, Detroit, Michigan;

${ }^{6}$ Department of Hematology and Oncology, Cleveland Clinic, Cleveland, Ohio; and

${ }^{7}$ Department of Neurosurgery, ${ }^{8}$ Department of Medical Education, and

${ }^{9}$ Department of Radiation Oncology, University of Michigan, Ann Arbor, Michigan.

\section{Background}

More than one-third of patients with metastatic nonsmall cell lung cancer (mNSCLC) will develop bone metastases during the course of their illness. ${ }^{1}$ Development of bone metastases often leads to significant morbidity, with approximately $70 \%$ of patients needing opioids for pain. ${ }^{2}$ The presence of bone metastases also increases the risk for skeletal-related events (SREs), including pathologic fracture. The prognostic significance of bone metastases with respect to mortality is unclear, with one recent metaanalysis of patients with mNSCLC treated with chemotherapy reporting that bone metastases were associated with improved overall survival (OS) compared with other metastatic sites. ${ }^{3}$

Few studies have evaluated the prognostic significance of bone metastases in the setting of immune checkpoint inhibitors (ICIs), although data show that bone metastases may be less responsive to ICIs. ${ }^{4,5}$ Prior studies of bone metastases and immunotherapy have been limited to specific patient populations, including those receiving specific lines of therapy and types of ICI, and did not include assessment of SREs or impact of use of bone-modifying agents (BMAs). ${ }^{6,7}$ Bone may represent an immunosuppressive tumor microenvironment, thereby limiting the efficacy of ICIs. ${ }^{8}$ Mechanisms of immunosuppression include the disruption of the osteoblastosteoclast remodeling cycle to induce a favorable growth environment for metastases, a decreased population of cytotoxic $\mathrm{T}$ cells and natural killer cells, and an increased population of suppressive immune cells, such as regulatory $\mathrm{T}$ cells and myeloid-derived suppressor cells. ${ }^{9}$

See JNCCN.org for supplemental online content. 
The FDA has approved the use of BMA, including bisphosphonates (pamidronate and zoledronic acid) and denosumab (a monoclonal antibody against RANKL), for the management of bone metastases in all solid tumors, and the NCCN Clinical Practice Guidelines in Oncology (NCCN Guidelines) for Non-Small Cell Lung Cancer (Version 6.2020) recommend consideration of these therapies in patients with mNSCLC who have bone metastases. ${ }^{10}$ Much of the data are extrapolated from large clinical trials in breast cancer, prostate cancer, and multiple myeloma. In lung cancer, zoledronic acid and denosumab reduce the risk of SREs ${ }^{11,12}$ and serve as an adjunctive therapy to palliative radiation to control pain. ${ }^{11}$ Retrospective analysis does not suggest that zoledronic acid improves survival in NSCLC, unlike in multiple myeloma, and an exploratory analysis suggested that denosumab was associated with an improvement in survival compared with zoledronic acid. ${ }^{13,14}$ The ability of BMAs to prevent SREs, and their impact on survival in the era of ICIs in patients with mNSCLC has not been studied.

We examined the impact of bone metastases and SREs on OS in patients with mNSCLC treated using ICIs, and evaluated the use of BMAs and their impact on survival and SREs. In addition to corroborating prior published studies examining the prognostic significance of bone metastases and determining the prognostic impact of bone metastases in the setting of different treatment modalities, we also evaluated a cohort of patients with mNSCLC treated with chemotherapy alone in whom we also recorded the incidence of bone metastases.

\section{Patients and Methods}

\section{$\mathrm{ICl}$ Cohort}

All patients who received ICIs for mNSCLC at University of Michigan and The Ohio State University between 2014 and 2017 were included in this retrospective analysis. These studies were approved by the Institutional Review Boards of both institutions. Patient demographics, disease characteristics (stage, histology, genomic alterations, metastatic burden [defined as the number of metastatic organ systems involved: $1,2, \geq 2]$ ), treatment received (including ICIs and BMAs), PD-L1 status when known, and response to treatment were all collected in a REDCap database. ${ }^{15}$ The presence of bone metastases was assessed on routine imaging obtained as part of standard of care before ICI initiation; for the purpose of this study, we defined baseline bone metastases as the presence before initiation of ICI treatment. SREs included pathologic bone fracture, palliative osseous radiation, or surgical intervention. OS was calculated from the date of ICI initiation until the date of death from any cause or was censored at loss to follow-up. Median OS with $95 \%$ confidence intervals was estimated using the
Kaplan-Meier method. OS was compared between patients with and without baseline bone metastases using a log-rank test. A Cox regression model was used to study the association between OS and baseline bone metastases, controlling for ECOG performance status, cancer histology, line of therapy, and metastatic burden. Patient characteristics were summarized and compared between those with and without SREs using the Fisher exact test for the categorical risk factors and the Kruskal-Wallis test for the continuous variables. All statistical analyses were performed using SAS, version 9.4 (SAS Institute Inc).

\section{Chemotherapy-Only Cohort}

An independent cohort of patients with mNSCLC treated using chemotherapy alone at University of Michigan in 2014 through 2017 were included in this analysis, which was approved by the Institutional Review Board. Information on patient demographics, histology, and chemotherapy regimen used was collected. Patients were divided into those with and without bone metastases, and OS data were collected. Patient date of death and time to progression were used to generate Kaplan-Meier plots of OS followed by logrank tests. Date of death was used as a primary endpoint. Patients still alive were censored at the time of last follow-up. Median and 95\% confidence intervals for OS were reported.

\section{Results}

\section{Patient Characteristics}

A total of 330 patients with mNSCLC who received ICIs were identified. Median age was 63.4 years, 156 patients $(47 \%)$ were male, $289(88 \%)$ were current or former smokers, 219 (66\%) had adenocarcinoma histology, and 211 (64\%) received nivolumab (Table 1). Of all patients included, 124 (38\%) had baseline bone metastases at ICI initiation. There were no significant differences between patients with versus without bone metastases in terms of sex $(P=.753)$, smoking status $(P=.838)$, histology $(P=.490)$, or line of therapy $(P=.567)$ (see supplemental eTable 1, available with this article at JNCCN.org). Median OS for the entire cohort was 10 months (95\% CI, 8.4-12.0). PD-L1 by tumor proportion score was positive in 68 patients $(20.6 \%)$, negative in $28(8.5 \%)$, and unknown in 234 (70.9\%), with no significant differences between patients with versus without bone metastases (supplemental eTable 1). Of the 124 patients with baseline bone metastases, 65 had received prior radiation, and no significant difference in survival was observed in these patients compared with those who had not received radiation $(P=.187)$.

\section{SRE Incidence and Risk Factors}

SREs occurred in 43 patients in the entire cohort (13\%), with a median time to SRE of 2.8 months. Histology, the presence of specific oncogenic mutations (KRAS, EGFR, 


\begin{tabular}{|c|c|}
\hline & n (\%) \\
\hline Total, N & 330 \\
\hline Median age at $\mathrm{ICl}, \mathrm{y}$ & 63.4 \\
\hline \multicolumn{2}{|l|}{ Sex } \\
\hline Male & $156(47)$ \\
\hline Female & $174(53)$ \\
\hline \multicolumn{2}{|l|}{ Smoking } \\
\hline Never & $41(12)$ \\
\hline Current/Former & $289(88)$ \\
\hline \multicolumn{2}{|l|}{ Histology } \\
\hline Adenocarcinoma & $219(66)$ \\
\hline Squamous & $86(26)$ \\
\hline Other & $25(8)$ \\
\hline \multicolumn{2}{|l|}{ Line of $\mathrm{ICl}$} \\
\hline First & $91(28)$ \\
\hline Second & $160(48)$ \\
\hline$\geq$ Third & $79(24)$ \\
\hline \multicolumn{2}{|l|}{ Type of $\mathrm{ICl}$} \\
\hline Nivolumab & $211(64)$ \\
\hline Pembrolizumab & $55(17)$ \\
\hline Atezolizumab & $22(6)$ \\
\hline Other & $42(13)$ \\
\hline Baseline BM & $124(38)$ \\
\hline
\end{tabular}

Abbreviations: $\mathrm{BM}$, bone metastases; $\mathrm{ICl}$, immune checkpoint inhibitor; mNSCLC, metastatic non-small cell lung cancer.

TP53), sex, and age were not predictive for the development of SREs (Table 2). Median duration of ICI treatment in patients who developed SREs was 2.5 months (interquartile range, 1.3-7.9) and was not significantly different compared with those who did not develop SREs (2.3 months; IQR, 0.9-7.2; $P=.790$ ). The only predictive factors identified in the entire cohort were the presence of baseline bone metastases $(P<.001)$ and the development or progression of bone metastases after ICI initiation $(P<.001)$. Therefore, a subgroup analysis of risk factors for SREs was conducted only in the 124 patients with baseline bone metastases (Table 3). Age, sex, histology, mutational status, ECOG performance status, and PD-L1 were not associated with risk of SREs in patients with bone metastases.

\section{BMA Use and SREs}

Of the 124 patients with bone metastases at baseline, 65 (52\%) received BMAs. There was no significant association between use of BMAs and development of SREs $(P=.84)$.

\section{Bone Metastases and Survival}

Patients with baseline bone metastases had shorter survival compared with those without bone metastases, with a median OS of 5.9 months (95\% CI, 4.2-7.8) versus 13.4 months (95\% CI, 10.8-17.0; $P<.001$ ), respectively (Figure 1). Patients with baseline bone metastases also had a higher hazard of death than those without after controlling for ECOG performance status, histology, line of therapy, and metastatic burden (hazard ratio, 1.57; 95\% CI, 1.19-2.08; $P=.001$ ). Development of SREs, irrespective of baseline bone metastases status, was associated with a shorter OS (median, 7.5 months [95\% CI, 4.6-10.0] vs 10.6 months [95\% CI, 8.4-12.8]; $P=.041)$. Use of BMAs in 65 patients did not impact OS $(P=.778)$, and the type of BMA used (bisphosphonates, $\mathrm{n}=37$; denosumab, $\mathrm{n}=28)$ was not correlated with $\mathrm{OS}(P=.622)$.

\section{Prognostic Significance of Bone Metastases in Patients Treated With Chemotherapy Alone} A total of 166 patients with mNSCLC treated with chemotherapy alone at the University of Michigan were evaluated in the chemotherapy-only cohort. Median age at chemotherapy was 66 years, 90 patients $(54.2 \%)$ were male, $141(85 \%)$ were former or current smokers, 131 (78.9\%) had adenocarcinoma histology, and the most common treatment regimen was carboplatin/pemetrexed (supplemental eTable 2). There was no statistically significant difference in survival between patients with or without bone metastases treated with chemotherapy alone (median OS, 15.4 vs 12.8 months, respectively; $P=.757$; Figure 2 ).

\section{Discussion}

In our multi-institutional study of patients with mNSCLC treated with ICIs, the presence of bone metastases was an independent adverse prognostic factor associated with worse OS after controlling for ECOG performance status, cancer histology, and line of therapy. Our finding is strengthened by our observation that, when accounting for metastatic burden, the presence of bone metastases was still a negative prognostic factor. In a separate independent cohort of patients treated with chemotherapy only, we found that the presence of bone metastases did not have any prognostic significance with respect to survival, corroborating prior studies. ${ }^{3}$ This analysis supports that bone metastases convey a different prognostic significance depending on treatment modality (chemotherapy vs immunotherapy) and adds to the literature supporting the negative impact of bone metastases in the era of checkpoint inhibition in mNSCLC. To our knowledge, this is the first study to show the negative impact of bone metastases regardless of line of therapy, and the first to explore the relationship between BMA use, SREs, and outcomes in these patients. 
Table 2. Risk Factors for Development of SREs

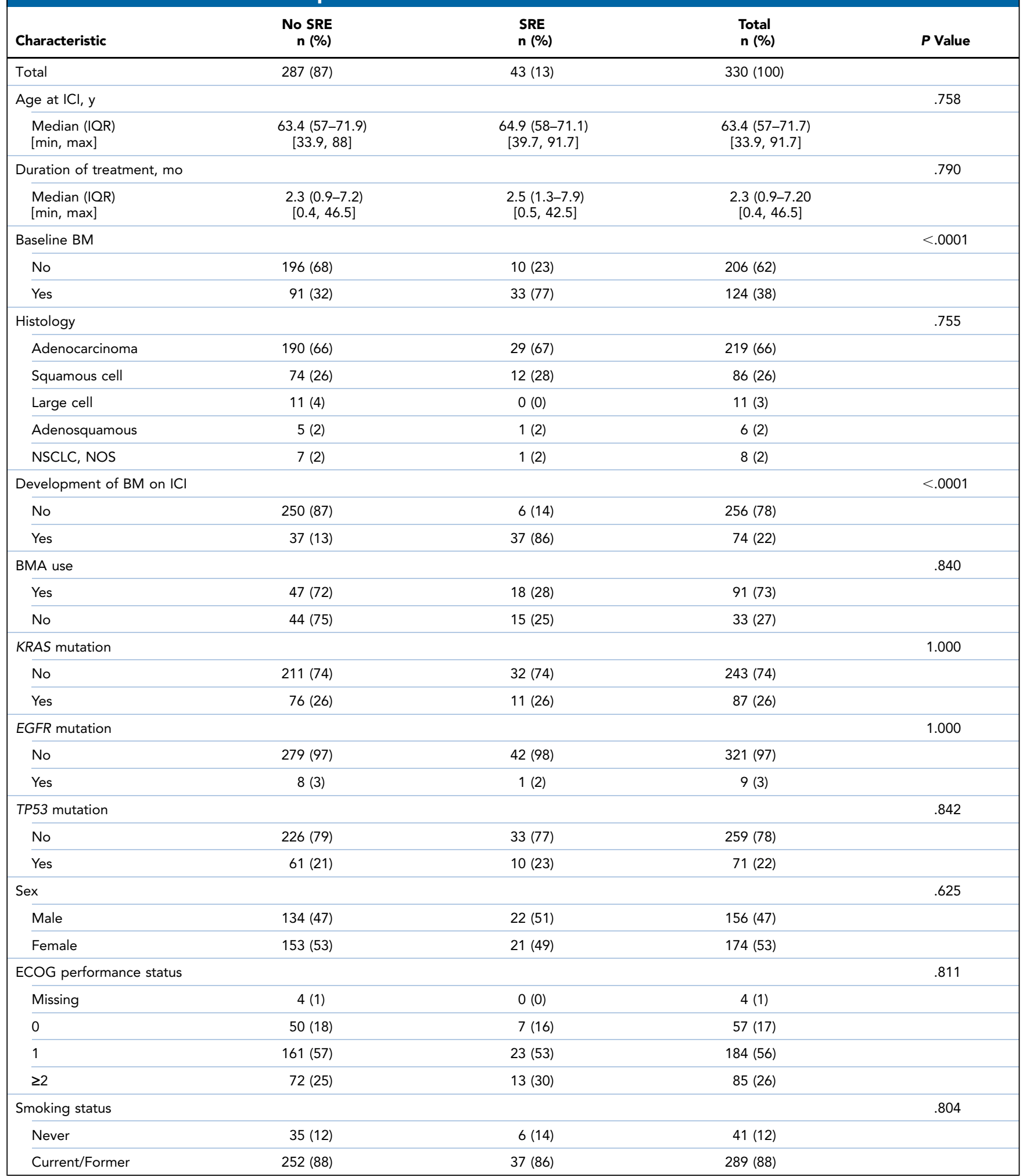

Abbreviations: BM, bone metastases; BMA, bone-modifying agent; ICI, immune checkpoint inhibitor; IQR, interquartile range; max, maximum; min, minimum; NOS, not otherwise specified; NSCLC, non-small cell lung cancer; SRE, skeletal-related event. 


\begin{tabular}{|c|c|c|c|c|}
\hline Age at $I C l, y$ & & & & .473 \\
\hline $\begin{array}{l}\text { Median (IQR) } \\
{[\mathrm{min}, \max ]}\end{array}$ & $\begin{array}{c}63.2(56.3-71.3) \\
{[33.9,86.8]}\end{array}$ & $\begin{array}{c}65(57.4-71.1) \\
{[39.7,91.7]}\end{array}$ & $\begin{array}{c}63.5(56.8-71.2) \\
{[33.9,91.7]}\end{array}$ & \\
\hline Male & $45(49.5)$ & $15(45.5)$ & $60(48.4)$ & \\
\hline Female & $46(50.5)$ & $18(54.5)$ & $64(51.6)$ & \\
\hline Histology & & & & .675 \\
\hline Adenocarcinoma & $60(65.9)$ & $22(66.7)$ & $82(66.1)$ & \\
\hline No & $67(73.6)$ & $23(69.7)$ & $90(72.6)$ & \\
\hline Yes & $24(26.4)$ & $10(30.3)$ & $34(27.4)$ & \\
\hline EGFR mutation & & & & .790 \\
\hline No & 89 (97.8) & $32(97)$ & $121(97.6)$ & \\
\hline Yes & $2(2.2)$ & $1(3.0)$ & $3(2.4)$ & \\
\hline Smoking status & & & & .876 \\
\hline Never & $12(13.2)$ & $4(12.1)$ & $16(12.9)$ & \\
\hline Current/Former & 79 (86.8) & $29(87.9)$ & $108(87.1)$ & \\
\hline ECOG PS & & & & .995 \\
\hline Missing & $70(76.9)$ & $21(63.6)$ & $91(73.4)$ & \\
\hline Negative & $10(11.0)$ & $2(6.1)$ & $12(9.7)$ & \\
\hline Positive & $11(12.1)$ & $10(30.3)$ & $21(16.9)$ & \\
\hline
\end{tabular}

Abbreviations: ICl, immune checkpoint inhibitor; IQR, interquartile range; PS, performance status; SRE, skeletal-related event.

ICIs are now approved as first-line treatment either alone or in combination with chemotherapy for most patients with mNSCLC. ${ }^{16}$ Emerging data suggest that different sites of metastases may portend different prognostic significance. In a large retrospective study of 1,025 patients with mNSCLC treated using ICIs, a multivariable analysis showed that brain metastases were not associated with worse OS, ${ }^{17}$ similar to findings in patients treated with chemotherapy. ${ }^{18}$ However, liver metastases, which are also common in mNSCLC, have been associated with poor prognostic significance in patients treated using both chemotherapy and ICIs. ${ }^{4,9}$ Recently, malignant pleural effusion has also been shown to be a predictor of poor outcomes in patients treated with ICIs. ${ }^{19,20}$ In addition to the sites of disease involved, several indices of inflammation derived from routine blood testing have also been explored, ${ }^{21}$ although these biomarkers are broadly prognostic and do not seem to be specifically predictive for immunotherapy.

Preclinical data suggest that the bone tumor microenvironment is immunosuppressive, thereby potentially negating the effect of ICIs. ${ }^{8}$ Although prior studies have shown that liver and brain metastases hold the same prognostic significance irrespective of treatment type, in our study, bone metastases stand out given their different impact depending on treatment modality.

Current clinical practice, informed by the NCCN Guidelines, ${ }^{10}$ recommends the use of specific antineoplastic therapy in eligible patients with mNSCLC; bisphosphonates 


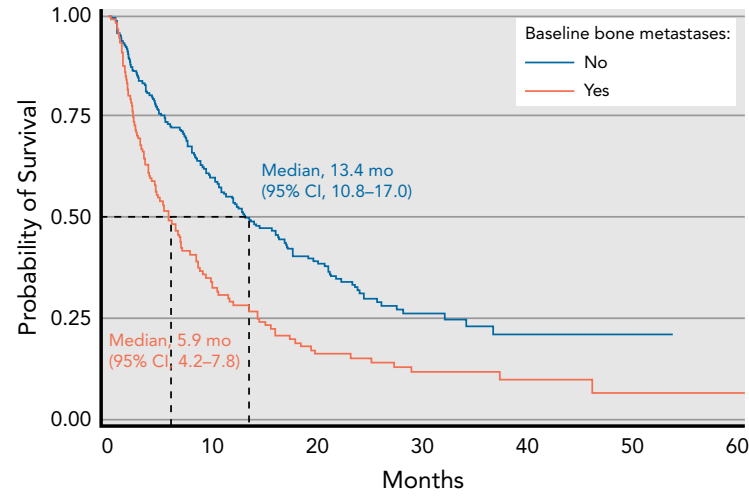

Figure 1. Kaplan-Meier curve of patients with mNSCLC treated using $\mathrm{ICl}$. Patients with bone metastases before $\mathrm{ICl}$ initiation had a statistically significant worse OS than those without bone metastases. Abbreviations: $\mathrm{ICl}$, immune checkpoint inhibitor; mNSCLC, metastatic nonsmall cell lung cancer; OS, overall survival.

or denosumab may be considered for those with bone metastases. ${ }^{16}$ Although zoledronic acid has been shown to delay time to SRE, it has not been shown to improve OS. ${ }^{22}$ Denosumab was shown to be noninferior to zoledronic acid with respect to delaying the onset of SREs, and a subgroup exploratory analysis suggested an OS advantage compared with zoledronic acid. ${ }^{11}$ In preclinical models and small studies, synergy between BMAs and ICIs has also been suggested. ${ }^{23,24}$ In our study, however, we found no association between BMA use and incidence of SREs, and observed no impact on survival. Although the overall number of patients who received BMAs was small, the lack of an association with incidence of SREs lends further credence to our finding that the presence of bone metastases conveys a negative prognostic significance with the use of immunotherapy in terms of both morbidity and mortality. Finally, the use of BMAs in just more than half of patients with bone metastases suggests widespread variability in the use of BMAs in patients with mNSCLC and bone metastases. Although the differing patterns of BMA use have been observed in prior studies, ${ }^{25}$ as the median duration of survival continues to improve with the changing treatment landscape for mNSCLC, ${ }^{26}$ the ability to delay and prevent SREs will remain vital to minimize these life-changing or life-limiting events.

Although our study is the largest study to address this question, a major limitation is its retrospective nature. Most patients received ICIs as second-line therapy, but the standard of care over the past 2 years has moved to ICIs as first-line treatment (either alone or in combination with chemotherapy). Therefore, our observation needs to be validated in the present treatment paradigm. We also did not specifically evaluate patients with bone metastases as the sole site of metastatic disease. The lack of known

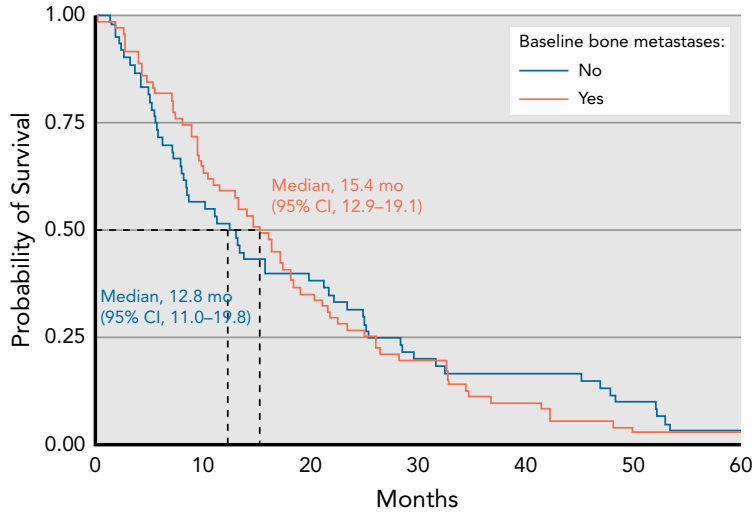

Figure 2. Kaplan-Meier curve of patients with mNSCLC treated using chemotherapy alone. There was no difference in OS regardless of the presence of bone metastases.

Abbreviations: mNSCLC, metastatic non-small cell lung cancer; OS, overall survival.

PD-L1 status for all patients is a further limitation. Finally, we did not measure response in the bone, which can be problematic with current imaging techniques. ${ }^{27}$

\section{Conclusions}

Our study contributes to the increasing body of evidence showing that the benefit of ICIs is partly determined by the involved site(s) of disease. In our study, patients treated with ICIs who had bone metastases had shorter survival than those without, and may represent a population at risk of poor outcomes from ICIs to be considered for further study. Finally, use of BMAs was not associated with a reduced risk of SREs or survival, although the patterns of use varied significantly.

\section{Acknowledgments}

This study was made possible through the REDCap project.

Submitted April 30, 2020; final revision received September 17, 2020; accepted for publication October 7, 2020. Published online April 20, 2021.

Author contributions: Study concept: Qin, Owen. Data collection: Qin Grogan, Szerlip, Chopra, Journey, Waninger, Green, Owen. Data analysis: Qin, Zhao, Wei, Green, Owen. Data review: Spakowicz. Patient treatment: Miah, Patel, Johns, Bertino, He, Shields, Kalemkerian, Gadgeel, Ramnath, Schneider, Hassan, Carbone, Presley, Otterson. Manuscript writing: Qin Manuscript review: Zhao, Miah, Wei, Patel, Johns, Grogan, Bertino, He, Shields, Kalemkerian, Gadgeel, Ramnath, Schneider, Hassan, Szerlip, Chopra, Journey, Waninger, Spakowicz, Carbone, Presley, Otterson, Green, Owen.

Disclosures: Dr. Qin disclosed receiving personal fees from Boehringer Ingelheim, and grant/research support from Clovis, Merck, and Takeda. Dr. Bertino disclosed receiving personal fees from Boehringer Ingelheim and Takeda. Dr. He disclosed receiving personal fees from Perthera and

Geneplus, and grant/research support from Bristol Myers Squibb, Mirati Therapeutics, Adaptimmune, and Genentech/Roche. Dr. Kalemkerian disclosed receiving grant/research support from Merck, GlaxoSmithKline, Takeda, and AbbVie. Dr. Gadgeel disclosed receiving nonfinancial support from AstraZeneca and Genentech/Roche; receiving personal fees from AbbVie, AstraZeneca, Bristol Myers Squibb, Genentech/Roche, Pfizer, and Takeda; receiving grant/research support from Merck, Blueprint Medicines, Aeglea Biotherapeutics, Astellas Pharma, G1 Therapeutics, Genentech/Roche, Lycera, Daiichi Sankyo, Pfizer, and Takeda; and serving as a scientific advisor for 
Merck, Genentech/Roche/AstraZeneca, and Bristol Myers Squibb. Dr. Ramnath disclosed receiving grant/research support from Merck and Clovis. Dr. Schneider disclosed receiving personal fees from Genentech/Roche, and grant/research support from Genentech/Roche, Medlmmune, OncoMed, Bristol Myers Squibb, and Macrogenics. Dr. Carbone disclosed receiving grant/ research support from Bristol Myers Squibb, and personal fees from AstraZeneca, Bayer, Biothera, Boehringer Ingelheim, Bristol Myers Squibb, Clovis, Genentech/Roche, Merck, Novartis, Peregrine Pharmaceuticals, Pfizer, Synta, Helsinn Therapeutics, AbbVie, Inivata, Loxo, Incyte, and Nexus Pharmaceuticals. Dr. Presley has disclosed being a Paul Calabresi Scholar supported by the Ohio State University K12 Training Grant for Clinical Faculty Investigators (5K12 CA133250-09) and the OSUCCC Pelotonia Junior Investigator Award. Dr. Otterson disclosed receiving grant/research support from Genentech/Roche, Bristol Myers Squibb, Clovis, Merck, Novartis, Pfizer, AstraZeneca, Acerta Pharma, and Ignyta; and personal fees from Novartis, Takeda, and Novocure. Dr. Owen disclosed receiving grant/research support from the Paul Calabresi Scholar program, Ohio State University K12 Training
Grant for Clinical Faculty Investigators (5K12 CA133250-09), Genentech/ Roche, Bristol Myers Squibb, Merck, Palobiofarma, and AbbVie; and personal fees from the Mednet and AstraZeneca. The remaining authors have disclosed that they have not received any financial consideration from any person or organization to support the preparation, analysis, results, or discussion of this article.

Funding: Research reported in this article was supported by the $\mathrm{NCl}$ of the $\mathrm{NIH}$ (number P30CA016058). This study was also supported by the Ohio State University Center for Clinical and Translational Science grant support (National Center for Advancing Translational Sciences, grant UL1TR002733).

Disclaimer: The content is solely the responsibility of the authors and does not necessarily represent the official views of the $\mathrm{NIH}$.

Correspondence: Angel Qin, MD, Division of Hematology and Oncology, University of Michigan, 1500 East Medical Center Drive, Med Inn-C353 SPC 5848, Ann Arbor, Ml 48103. Email: qina@med.umich.edu

\section{References}

1. Cetin K, Christiansen CF, Jacobsen JB, et al. Bone metastasis, skeletalrelated events, and mortality in lung cancer patients: a Danish populationbased cohort study. Lung Cancer 2014;86:247-254.

2. Hendriks LE, Hermans $B C$, van den Beuken-van Everdingen $M H$, et al. Effect of bisphosphonates, denosumab, and radioisotopes on bone pain and quality of life in patients with non-small cell lung cancer and bone metastases: a systematic review. J Thorac Oncol 2016;11:155-173.

3. Bates JE, Milano MT. Prognostic significance of sites of extrathoracic metastasis in patients with non-small cell lung cancer. J Thorac Dis 2017;9: 1903-1910.

4. Osorio JC, Arbour KC, Le DT, et al. Lesion-level response dynamics to programmed cell death protein (PD-1) blockade. J Clin Oncol 2019;37: 3546-3555.

5. Schmid S, Diem S, Li Q, et al. Organ-specific response to nivolumab in patients with non-small cell lung cancer (NSCLC). Cancer Immunol Immunother 2018;67:1825-1832.

6. Cortellini A, Tiseo M, Banna GL, et al. Clinicopathologic correlates of firstline pembrolizumab effectiveness in patients with advanced NSCLC and a PD-L1 expression of $\geq 50 \%$. Cancer Immunol Immunother 2020;69: 2209-2221.

7. Landi L, D'Incà F, Gelibter A, et al. Bone metastases and immunotherapy in patients with advanced non-small-cell lung cancer. J Immunother Cancer 2019;7:316.

8. Reinstein ZZ, Pamarthy S, Sagar V, et al. Overcoming immunosuppression in bone metastases. Crit Rev Oncol Hematol 2017;117:114-127.

9. Jiao S, Subudhi SK, Aparicio A, et al. Differences in tumor microenvironment dictate $T$ helper lineage polarization and response to immune checkpoint therapy. Cell 2019;179:1177-1190.e13.

10. Ettinger DS, Wood DE, Aisner DL, et al. NCCN Clinical Practice Guidelines in Oncology: Non-Small Cell Lung Cancer. Version 6.2020. Accessed August 10, 2020. To view the most recent version, visit NCCN.org

11. Henry DH, Costa L, Goldwasser F, et al. Randomized, double-blind study of denosumab versus zoledronic acid in the treatment of bone metastases in patients with advanced cancer (excluding breast and prostate cancer) or multiple myeloma. J Clin Oncol 2011;29:1125-1132.

12. Rosen LS, Gordon D, Tchekmedyian NS, et al. Long-term efficacy and safety of zoledronic acid in the treatment of skeletal metastases in patients with nonsmall cell lung carcinoma and other solid tumors: a randomized, phase III, double-blind, placebo-controlled trial. Cancer 2004;100: 2613-2621.

13. Decroisette $\mathrm{C}$, Monnet I, Berard H, et al. Epidemiology and treatment costs of bone metastases from lung cancer: a French prospective, observational, multicenter study (GFPC 0601). J Thorac Oncol 2011;6: 576-582.

14. Scagliotti GV, Hirsh V, Siena S, et al. Overall survival improvement in patients with lung cancer and bone metastases treated with denosumab versus zoledronic acid: subgroup analysis from a randomized phase 3 study. J Thorac Oncol 2012;7:1823-1829.
15. Harris PA, Taylor R, Thielke R, et al. Research electronic data capture (REDCap) - a metadata-driven methodology and workflow process for providing translational research informatics support. J Biomed Inform 2009;42:377-381.

16. Ettinger DS, Wood DE, Aggarwal C, et al. NCCN Guidelines Insights: Non-Small Cell Lung Cancer, Version 1.2020. J Natl Compr Canc Netw 2019;17:1464-1472.

17. Hendriks LEL, Henon C, Auclin E, et al. Outcome of patients with nonsmall cell lung cancer and brain metastases treated with checkpoint inhibitors. J Thorac Oncol 2019;14:1244-1254.

18. Tamura T, Kurishima K, Nakazawa K, et al. Specific organ metastases and survival in metastatic non-small-cell lung cancer. Mol Clin Oncol 2015;3: 217-221.

19. Kawachi H, Tamiya M, Tamiya A, et al. Association between metastatic sites and first-line pembrolizumab treatment outcome for advanced nonsmall cell lung cancer with high PD-L1 expression: a retrospective multicenter cohort study. Invest New Drugs 2020;38:211-218.

20. Pantano F, Russano M, Berruti A, et al. Prognostic clinical factors in patients affected by non-small-cell lung cancer receiving nivolumab. Expert Opin Biol Ther 2020;20:319-326.

21. Sorich MJ, Rowland A, Karapetis CS, et al. Evaluation of the Lung Immune Prognostic Index for prediction of survival and response in patients treated with atezolizumab for NSCLC: pooled analysis of clinical trials. J Thorac Oncol 2019;14:1440-1446.

22. Rosen LS, Gordon D, Tchekmedyian S, et al. Zoledronic acid versus placebo in the treatment of skeletal metastases in patients with lung cancer and other solid tumors: a phase III, double-blind, randomized trial-the Zoledronic Acid Lung Cancer and Other Solid Tumors Study Group. J Clin Oncol 2003;21:3150-3157.

23. Angela Y, Haferkamp S, Weishaupt $C$, et al. Combination of denosumab and immune checkpoint inhibition: experience in 29 patients with metastatic melanoma and bone metastases. Cancer Immunol Immunother 2019;68:1187-1194.

24. Li Y, Du Y, Sun T, et al. PD-1 blockade in combination with zoledronic acid to enhance the antitumor efficacy in the breast cancer mouse model. BMC Cancer 2018;18:669.

25. Udagawa H, Niho S, Kirita K, et al. Impact of denosumab use on the survival of untreated non-squamous non-small cell lung cancer patients with bone metastases. J Cancer Res Clin Oncol 2017;143:1075-1082.

26. Gandhi L, Rodríguez-Abreu D, Gadgeel S, et al. Pembrolizumab plus chemotherapy in metastatic non-small-cell lung cancer. N Engl J Med 2018;378:2078-2092.

27. Gomi D, Fukushima T, Kobayashi T, et al. Fluorine-18fluorodeoxyglucose-positron emission tomography evaluation in metastatic bone lesions in lung cancer: possible prediction of pain and skeletalrelated events. Thorac Cancer 2019;10:980-987. 
Supplemental online content for:

\section{Bone Metastases, Skeletal-Related Events, and Survival in Patients With Metastatic Non-Small Cell Lung Cancer Treated With Immune Checkpoint Inhibitors}

Angel Qin, MD; Songzhu Zhao, MSc; Abdul Miah, MD; Lai Wei, PhD; Sandipkumar Patel, MBBS;

Andrew Johns, MD; Madison Grogan, BA; Erin M. Bertino, MD; Kai He, MD, PhD; Peter G. Shields, MD; Gregory P. Kalemkerian, MD; Shirish M. Gadgeel, MBBS; Nithya Ramnath, MBBS; Bryan J. Schneider, MD; Khaled A. Hassan, MD, MS; Nicholas Szerlip, MD; Zoey Chopra, BA; Sara Journey, BS; Jessica Waninger, BA, BS; Daniel Spakowicz, PhD; David P. Carbone, MD, PhD; Carolyn J. Presley, MD, MHS; Gregory A. Otterson, MD; Michael D. Green, MD, PhD; and Dwight H. Owen, MD, MSc

J Natl Compr Canc Netw 2021;19(8):915-921

eTable 1: Characteristics of Patients With mNSCLC Treated Using ICls

eTable 2: Characteristics of Patients With mNSCLC Treated Using Chemotherapy Only 


\begin{tabular}{|c|c|c|c|c|}
\hline Median age at ICI (IQR), y & $63.4(57.6-72.7)$ & $63.5(56.8-71.2)$ & $63.4(57.3-71.7)$ & .646 \\
\hline Sex & & & & .753 \\
\hline Histology & & & & .490 \\
\hline Adenocarcinoma & $137(66.5)$ & $82(66.1)$ & $219(66.4)$ & \\
\hline Squamous & $56(27.2)$ & $30(24.2)$ & $86(26.1)$ & \\
\hline Other & $13(6.3)$ & $12(9.7)$ & $25(7.6)$ & \\
\hline EGFR mutation & & & & .790 \\
\hline 0 & $200(97.1)$ & $121(97.6)$ & $321(97.3)$ & \\
\hline 1 & $6(2.9)$ & $3(2.4)$ & $9(2.7)$ & \\
\hline TP53 mutation & & & & .715 \\
\hline 0 & $163(79.1)$ & $96(77.4)$ & $259(78.5)$ & \\
\hline 1 & $43(20.9)$ & $28(22.6)$ & $71(21.5)$ & \\
\hline ECOG PS & & & & .519 \\
\hline Missing & 2 & 2 & 4 & \\
\hline 0 & $39(18.9)$ & $18(14.5)$ & $57(17.3)$ & \\
\hline Metastatic burden & & & & $<.001$ \\
\hline Missing & 0 & 1 & $1(0.3)$ & \\
\hline 1 & $90(43.7)$ & $19(15.5)$ & $109(33.1)$ & \\
\hline 2 & 76 (36.9) & $47(38.2)$ & $123(37.4)$ & \\
\hline$\geq 3$ & $40(19.4)$ & $57(46.3)$ & $97(29.5)$ & \\
\hline PD-L1 & & & & .262 \\
\hline Missing & $143(69.4)$ & $91(73.3)$ & $234(70.9)$ & \\
\hline Negative & $16(7.8)$ & $12(9.7)$ & $28(8.5)$ & \\
\hline Positive & $47(22.8)$ & $21(17.0)$ & $68(20.6)$ & \\
\hline Line of therapy & & & & .567 \\
\hline 1 & $57(27.7)$ & $34(27.4)$ & $91(27.6)$ & \\
\hline 2 & $96(46.6)$ & $64(51.6)$ & $160(48.5)$ & \\
\hline 3 & $53(25.7)$ & $26(21.0)$ & 79 (23.9) & \\
\hline
\end{tabular}

Abbreviations: BM, bone metastases; ICl, immune checkpoint inhibitor; IQR, interquartile ratio; mNSCLC, metastatic non-small cell lung cancer; PS, performance status. 


\begin{tabular}{|c|c|}
\hline Characteristic & n (\%) \\
\hline Total, N & 166 \\
\hline Age at therapy, $y$ & 66 \\
\hline \multicolumn{2}{|l|}{ Sex } \\
\hline Male & $90(54.2)$ \\
\hline Female & $76(45.8)$ \\
\hline \multicolumn{2}{|l|}{ Smoking status } \\
\hline Never & $25(15.1)$ \\
\hline Current/Former & $141(84.9)$ \\
\hline \multicolumn{2}{|l|}{ Histology } \\
\hline Adenocarcinoma & $131(78.9)$ \\
\hline Squamous & $22(13.3)$ \\
\hline Other & $13(7.8)$ \\
\hline \multicolumn{2}{|l|}{ Stage at therapy } \\
\hline IV & $166(100.0)$ \\
\hline \multicolumn{2}{|l|}{ Therapy } \\
\hline Carboplatin/Pemetrexed & 49 (29.5) \\
\hline Gemcitabine & $27(16.3)$ \\
\hline Carboplatin/Paclitaxel & $13(7.8)$ \\
\hline Pemetrexed & $15(9.0)$ \\
\hline EGFR inhibitors & $15(9.0)$ \\
\hline Other & $47(28.3)$ \\
\hline
\end{tabular}

Abbreviation: mNSCLC, metastatic non-small cell lung cancer. 